\title{
УДОСКОНАЛЕНА МАТЕМАТИЧНА МОДЕЛЬ ВІДЦЕНТРОВОГО РЕГУЛЯТОРА РОТОРА ВІТРОУСТАНОВКИ ПРИ ФЛЮГЕРНОМУ РЕГУЛЮВАННІ
}

\author{
В.М. Головко, проф., д-р. техн. наук, В.П. Коханєвич, канд. техн. наук, М.О. Шихайлов, наук. співроб., \\ Н.В. Марченко, мол. наук. співроб.
}

Інститут відновлюваної енергетики НАН України, 02094, вул. Гната Хоткевича, 20А, м. Київ, Україна.

Для регулювання та вимірювання обертів механізмів $і$ двигунів у різних галузях машинобудування та приладобудування широкого розповсюдження набули відцентрові регулятори. Найбільш фундаментальними дослідженнями в даній галузі $\epsilon$ праці Н.С. Жуковського, І.О. Вишнеградського, А. Стодоли та ін. Подальший розвиток й удосконалення вивчення иъого питання відображено в праці Л.М. Цукерника. Для вітроустановок Г.Х. Сабініним була запропонована схема відиентрового регулятора для флюгерного регулювання ГС-4, щэо була реалізована в ряді установок, а саме ВЭ-2, ВЭ-3, ВЭ-5. Дослідження подібних систем регулювання було проведено в КБ «Шторм» при НТУУ «КПІ», а в подальшому - в Інституті електродинаміки НАН Украӥни.

В Інституті відновлюваної енергетики була запропонована удосконалена схема регулятора ГС-4 і відповідна математична модель, а саме був введений змінний кут між хордою лопаті та віссю моменту інериї відиентрових тягариів (у регуляторі ГС-4 він був постійний і становив $90^{\circ}$ ).

Якщо на початку розвитку вітроенергетики технологічні можливості дозволяли отримати трапецієподібну форму лопаті без геометричного закруту хорди (або з незначним закрутом - до $4^{\circ}$...5 $5^{\circ}$ ), то в математичних моделях було правомірним допущення, що направлення моменту інериії лопаті збігається з хордою лопаті. Сучасна тенденція отримання максимального коефіцієнта використання енергї вітру ротором вимагає виготовлення лопаті, реальний профіль якої максимально наближений до розрахункового. Тобто в сучасних лопатях використовують розиирення лопаті від кіния до комеля в межах від 1:2 до 1:4 і закрут лопаті сягає $30^{\circ}$. Враховуючи все ие, можна констатувати, щэо відхилення направлення моменту інериії лопаті від хорди лопаті може складати до $20^{\circ}$. Тому без урахування даного кута математичні моделі відиентрового регулятора не є достатньо досконалими.

В даній роботі запропонована математична модель відчентрового регулятора ротора вітроустановки з урахуванням кута між вектором моменту інериї лопаті та ї̈ хордою, що дозволило отримати уточнений вираз для статичноі характеристики регулятора, а також уточнити вирази для визначення параметрів відчентрового регулятора, які використовуються при його налаштуванні для отримання необхідних номінальних обертів ротора вітроустановки. Бібл. 11, рис. 1.

Ключові слова: вітроенергетика, вітроустановка, відиентровий регулятор ротора вітроустановки.

\section{ADVANCED MATHEMATICAL MODEL OF THE CENTRIFUGAL REGULATOR OF THE WIND ROTOR WITH FLUGE CONTROL}

V. Golovko, professor, doctor of technical science, V. Kokhanevich, candidate of technical science,

M. Shykhailov, research assistant, N. Marchenko, junior researcher

Institute of Renewable Energy of the National Academy of Sciences of Ukraine,

02094, 20A Hnata Khotkevycha St., Kyiv, Ukraine.

Centrifugal regulators have become widespread in various fields of mechanical engineering and instrumentation for regulating and measuring the speed of mechanisms and motors. The most fundamental studies in this field are the works of N.E. Zhukovsky, I.O. Vyshegradsky, A. Stodola, and others. In the further development and generalization of the theory of centrifugal regulators acquired in the work of L.M. Tsukernik. For wind turbines, G.H. Sabinin proposed a centrifugal regulator scheme for weather vane control $\Gamma C-4$ and was implemented in a number of installations, namely BЭ-2, ВЭ-3, ВЭ-5. A number of studies of such control systems were conducted at the Storm Design Bureau at NTUU KPI, and later at the Institute of Electrodynamics of the National Academy of Sciences of Ukraine. 
The Institute of Renewable Energy proposed an improved scheme of the $Г C-4$ regulator and a corresponding mathematical model, namely, a variable angle between the blade chord and the axis of moment of inertia of centrifugal weights was introduced (in the $\Gamma C$ 4 regulator it was constant and was $90^{\circ}$ ).

If at the beginning of the development of wind power, technological capabilities made it possible to obtain a trapezoidal blade shape without geometric twisting of the chord (or with insignificant up to $4^{\circ} . . .5^{\circ}$ ), then in mathematical models it was legitimate to assume that the direction of the moment of inertia of the blade coincides with the chord of the blade. Today, the trend in the manufacture of a blade is aimed at obtaining the maximum utilization of wind energy by the rotor and, accordingly, the maximum approximation of the real blade profile to the calculated one. That is, in modern blades, blade expansion from end to butt is used in the range from 1:2 to 1:4, and the twisting of the chordi of the blade reaches $30^{\circ}$. Considering all this, it can be stated that the deviation of the direction of the moment of inertia of the blade from the chord of the blade can be up to $20^{\circ}$. Therefore, without taking into account this angle, the mathematical models of the centrifugal controller are not perfect enough.

In this paper we propose a mathematical model of the centrifugal regulator of the wind turbine rotor taking into account the angle between the vector of the moment of inertia of the blade and its chord, which allowed to obtain a refined expression for the static characteristics of the regulator speed of the wind turbine rotor. Bibl. 11, fig. 1 .

Keywords: wind power, wind turbine, centrifugal regulator of the rotor of the wind turbine.

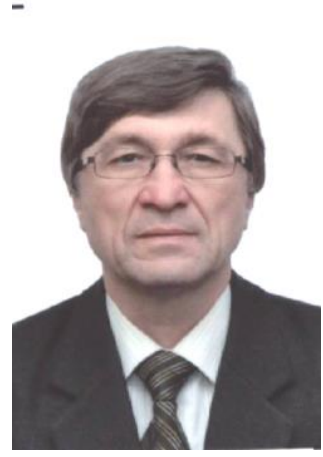

B.М. Головко V. Golovko

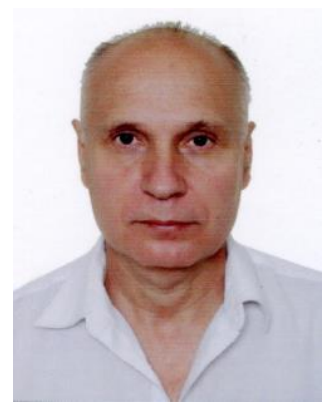

В.П. Коханєвич V. Kokhanievych

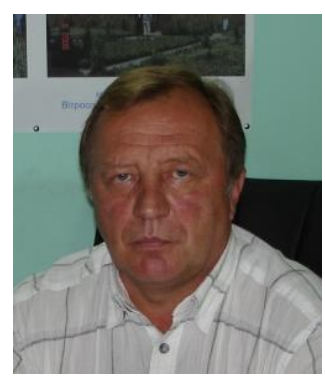

М.О. Шихайлов M. Shykhailov
Відомості про автора: провідний науковий співробітник Інституту відновлюваної енергетики НАН України

Освіта: Українська сільськогосподарська академія. Спеціальність «Електрифікація сільського господарства»

Наукова сфера: відновлювані джерела енергії, вітроенергетика, вітроустановки малої потужності, автономні системи енергозабезпечення

Публікації: 168

Контакти: тел./факс: +38(044)206-28-09

e-mail: renewable@ukr.net ORCID: 0000-0003-0195-9654

Відомості про автора: старший науковий співробітник Інституту відновлюваної енергетики НАН України

Освіта: Київський політехнічний інститут. Спеціальність «Технологія машинобудування, метало ріжучі верстати та інструменти»

Наукова сфера: вітроенергетика, вітроустановки малої потужності, системи регулювання та захисту

Публікації: 147

Контакти: тел./факс: +38(044)206-28-09

e-mail: renewable@ukr.net ORCID: 0000-0003-0033-1355

Відомості про автора: науковий співробітник Інституту відновлюваної енергетики НАН України.

Освіта: Київський політехнічний інститут. Спеціальність «Гідропневмоавтоматика та гидропривод»

Наукова сфера: вітроенергетика, вітроустановки малої потужності, системи управління

Публікації: 215

Контакти: тел./факс: +38(044)206-28-09

e-mail: renewable@ukr.net

ORCID: 0000-0003-1845-9904
Author information: chief researcher at Institute for Renewable Energy, National Academy of Sciences of Ukraine

Education: Ukrainian Agricultural Academy. Specialty «Electrification of agriculture» Research area: renewable sources of energy, wind power systems, small capacity wind units, autonomous power systems

Publications: 168

Contacts: phone/fax: +38(044)206-28-09

e-mail: renewable@ukr.net

ORCID: 0000-0003-0195-9654

Author information: senior researcher at Institute for Renewable Energy, National Academy of Sciences of Ukraine Education: Kyiv Polytechnic Institute. Specialty «Technology of mechanical engineering, metal cutting machines and tools» Research area: wind energy, low power wind turbines, control and protection systems Publications: 147

Contacts: phone/fax: +38(044)206-28-09

e-mail: renewable@ukr.net

ORCID: 0000-0003-0033-1355

Author information: researcher in at Institute for Renewable Energy, National Academy of Sciences of Ukraine

Education: Kyiv Polytechnic Institute.

Specialty «Hydropneumatic automation and hydraulic drive»

Research area: wind power systems, small capacity wind units, control systems

Publications: 215

Contacts: phone/fax: +38(044)206-28-09

e-mail: renewable@ukr.net

ORCID: 0000-0003-1845-9904 


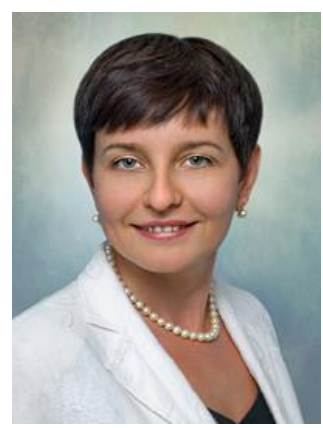

Н.В Марченко N. Marchenko
Відомості про автора: молодший науковий співробітник з питань маркетингових досліджень Інституту відновлюваної енергетики НАН України

Освіта: Інститут легкої промисловості. Спеціальність «Інженер-конструктортехнолог»

Наукова сфера: маркетингові дослідження в галузі відновлюваної енергетики, вітроустановки, пристрої $з$ постійними магнітами

Публикації: 33

ORCID: 0000-0001-9921-9077

Контакти: тел/факс:+38(098)408-26-02

e-mail: nadija08@ukr.net
Author information: Junior Researcher on marketing research at the Institute for Renewable Energy of the National Academy of Sciences of Ukraine

Education: Kyiv National University of Technologies and Design, specialty Design Engineer - Technologist

Research area: wind power systems, hydrogenerators, permanent magnets devices.

Publications: 33

ORCID: 0000-0001-9921-9077

Contacts: phone/fax:+38(098)408-26-02

e-mail: nadija08@ukr.net

Перелік використаних позначень та скорочень:

$\varphi$ - кут установлення лопаті, профілю елемента лопаті; $\varphi_{0}$ - початковий кут установлення лопаті;

$i$ - кількість лопатей;

$\omega$ - кутова швидкість обертання ротора;

$n$ - швидкість обертання ротора;

$\bar{n}$ - відносна швидкість обертання ротора;

$n_{\text {ном }}$ - номінальна швидкість обертання ротора;

$\Theta$ - кут між кривошипом і хордою лопаті;

$\Omega$ - кут між хордою лопаті й державками відцентрових тягарців;

$\Delta \varphi$ - кут між хордою лопаті й вектором моменту інерції лопаті;

Вступ. Відцентрові регулятори набули широкого розповсюдження в різних галузях машинобудування та приладобудування. Ї̈ застосовують для регулювання та вимірювання обертів механізмів і двигунів. Найбільш фундаментальними дослідженнями в даній галузі є праці Н.Є. Жуковського [1], I.O. Вишнеградського, А. Стодоли [2] та ін. Подальший розвиток та узагальнення теорія відцентрових регуляторів набула в праці Л.М. Цукерника [3]. Для вітроустановок Г.Х. Сабініним була запропонована схема відцентрового регулятора для флюгерного регулювання ГС-4 [4, 5], що була реалізована в ряді установок, а саме ВЭ-2, ВЭ-3, ВЭ-5 [6-8]. Дослідженння подібних систем регулювання були проведені в КБ «Шторм» при НТУУ «КПІ», а в подальшому - в Інституті електродинаміки НАН України [9, 10]. На полігоні «Десна» були встановлені вісім експериментальних вітроустановок ВЭД-15, на яких досліджувались режими роботи регуляторів.
$J_{T}$ - момент інерції відцентрових тягарців;

$J_{J}$ - момент інерції лопаті;

$F_{\Pi p_{0}}$ - величина початкового натягу пружини регулювання; $A$ - величина, яка характеризує величину початкового натягу пружини регулювання;

$\bar{A}$ - величина початкового натягу пружини регулювання, приведена до довжини кривошипа та жорсткості пружини; $k$ - жорсткість пружини регулювання;

$l$ - довжина кривошипа механізму регулятора.

В Інституті відновлюваної енергетики була запропонована вдосконалена схема регулятора ГC-4 і відповідна математична модель [11], а саме був введений змінний кут між хордою лопаті та віссю моменту інерції відцентрових тягарців (в регуляторі ГС-4 він був постійний i становив $90^{\circ}$ ). Отримані на основі даної моделі статичні характеристики відцентрового регулятора дозволяли на стадії проєктування визначати параметри регулятора, а також дали змогу визначити відхилення обертів ротора в заданому робочому діапазоні швидкостей вітру при різних навантаженнях.

Постановка завдання. Геометрія лопаті (форма лопаті в плані, зміна відносної товщини профілю, геометричний закрут лопаті) в сукупності з вибраним аеродинамічним профілем визначають ефективність ротора, а саме можливість досягати максимального за таких умов коефіцієнта використання енергії вітру. Якщо на початку розвитку вітроенергетики технологічні можливості виготовлення лопатей дозволяли отримати трапецієподібну форму без 
геометричного закруту хорди (або 3 незначним закрутом - до $4^{\circ} \ldots 5^{\circ}$ ), то в математичних моделях $[4,5,11]$ було правомірним допущення, що направлення моменту інерції лопаті збігається з хордою лопаті.

Розвиток технологічних можливостей виготовлення лопатей для вітроустановок суттєво вплинув на конструкцію та геометрію лопаті. Сучасна тенденція отримання максимального коефіцієнта використання енергії вітру ротором вимагає виготовлення лопаті, реальний профіль якої максимально наближений до розрахункового. Тобто в сучасних лопатях використовують розширення лопаті від кінця до комеля в межах від 1:2 до 1:4 і закрут лопаті сягає $30^{\circ}$. Отже, можна констатувати, що відхилення направлення моменту інерції лопаті від хорди лопаті може складати до $20^{\circ}$ i без урахування даного відхилення математична модель відцентрового регулятора є недостатньо досконалою, що може призвести до неправильних розрахунків його параметрів та всіх інших характеристик.

Результати досліджень. Статичний стан вітроустановки при регулюванні обертів ротора поворотом лопаті навколо іiі осі, зокрема й при відцентровому регулюванні, визначається двома рівняннями. Перше являє собою умову рівноваги між рушійним моментом ротора вітроустановки $\mathrm{i}$ моментом навантаження $M_{P}=M_{H}$ і розглянуто в [4]. Друге - умова рівноваги всіх сил, які обертають лопать відносно своєї осі. Повний вигляд цього рівняння:

$$
M_{A}+M_{B}+M_{\Pi p}+M_{T p}=0,
$$

де $M_{A}$ - момент аеродинамічних сил, що діють на лопать; $M_{B}-$ момент відцентрових сил; $M_{\Pi р}-$ момент пружини, приведений до осі лопаті; $M_{T p}-$ момент тертя.

У працях [4, 5, 11] проведено аналіз величин моментів аеродинамічних сил і моменту тертя та їхній вплив на роботу регулятора й прийнято припущення, які доцільно використати i в цьому разі, тобто можна прийняти що: $M_{A}=0 ; M_{T p}=0$.

На рис. 1. наведена схема сил при флюгерному регулюванні, що дозволяє визначити сили, які обертають лопать навколо їі осі. Для такого типу регулювання характерним $\epsilon$ дія в напрямку збільшення кута установлення лопаті, тому, відповідно, моменти, які діють в напрямку збільшення кутів установлення лопаті, будуть додатними, а в протилежному напрямку від’ємними.

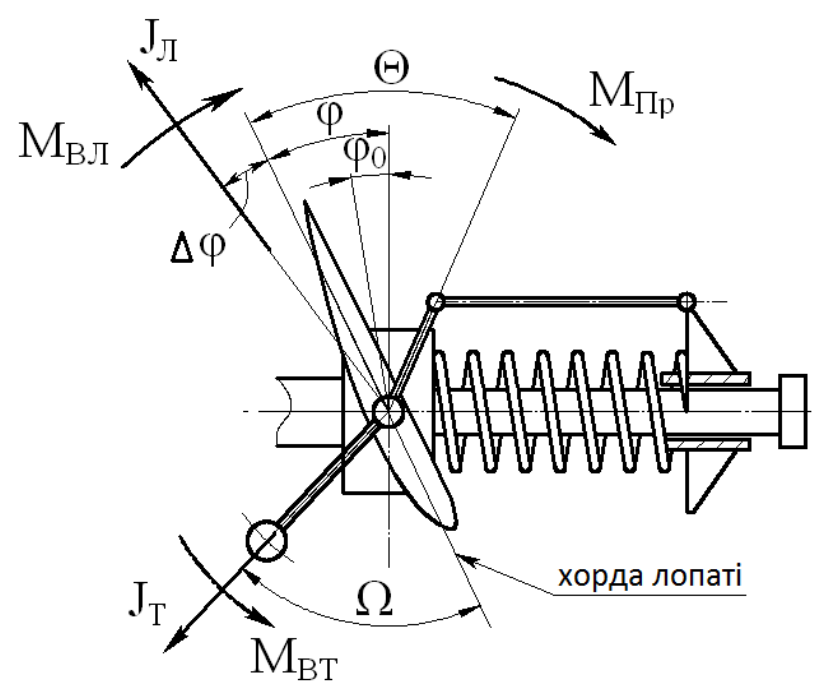

Рис. 1. Схема сил, що діють на лопать при флюгерному регулюванні

Fig. 1. Scheme of forces acting on the blade during weather vane adjustment 
Момент пружини, приведений до осі регулятора, що наведена в [11], а тому лопаті, не відрізняється від аналогічного моменту використаємо вираз для його визначення: для математичної моделі відцентрового

$$
M_{\Pi p}=-\frac{k}{i}\left\{a+l\left[\sin \mu_{0}-\sin \left(\mu_{0}-\left(\varphi-\varphi_{0}\right)\right)\right]\right\} l \cos \left(\mu_{0}-\left(\varphi-\varphi_{0}\right)\right),
$$

де $a=\frac{F_{П p_{0}}}{k}-$ величина, що характеризує величину початкового натягу пружини регулювання; $F_{П p_{0}}-$ величина початкового натягу пружини регулювання; $k$ - жорсткість пружини регулювання; $i$ - число лопатей; $\mu_{0}-$ кут між кривошипом і площиною обертання ротора при $\varphi_{0}\left(\mu_{0} \in\right.$ початковим кутом встановлення кривошипа); $\varphi$ - кут установлення лопаті (поточний); $\varphi_{0}$ - початковий кут установлення лопаті; $l$ - довжина плеча кривошипа механізму регулятора.

Позначимо кут між кривошипом і хордою лопаті через $\Theta[11]$, тоді: $\Theta=\mu_{0}+\varphi_{0}$; $\mu_{0}=\Theta-\varphi_{0} .3$ урахуванням даних виразів формула для $M_{\Pi р}$ набуде вигляду:

$$
M_{\Pi p}=-\frac{k}{i}\left\{a+l\left[\sin \left(\Theta-\varphi_{0}\right)-\sin (\Theta-\varphi)\right]\right\} l \cos (\Theta-\varphi) .
$$

Момент відцентрових сил системи регулювання $€$ сумою відцентрових моментів тягарців та лопаті:

$$
M_{B}=M_{B T}+M_{B Л} .
$$

Момент відцентрових сил лопаті становить:

$$
M_{B J}=-\frac{1}{2} J_{J} \omega^{2} \sin 2(\varphi+\Delta \varphi),
$$

де $J_{Л}-$ момент інерції лопаті; $\omega-$ кутова швидкість обертання ротора; $\Delta \varphi-$ кут між хордою лопаті й вектором моменту інерції лопаті.

Необхідно зауважити, що з урахуванням аеродинамічних розрахунків, геометричний закрут лопаті при флюгерному регулюванні направлений на збільшення кута $\varphi$ (див. рис. 1).
Момент відцентрових сил тягарців складає:

$$
M_{B T}=\frac{1}{2} J_{T} \omega^{2} \sin 2\left(\gamma_{0}-\left(\varphi-\varphi_{0}\right)\right),
$$

де $\gamma_{0}$ - кут між державками тягарців і площиною обертання ротора при $\varphi_{0}\left(\gamma_{0} \in\right.$ початковим кутом встановлення відцентрових тягарців); $J_{T}$ - момент інерції відцентрових тягарців.

Позначимо кут між хордою лопаті й державками відцентрових тягарців $\Omega$ [20], тоді $\Omega=\gamma_{0}+\varphi_{0}$, і вираз для $M_{B T}$ набуде вигляду:

$$
M_{B T}=\frac{1}{2} J_{T} \omega^{2} \sin 2(\Omega-\varphi) .
$$

3 урахуванням виразів (6) та (7) момент відцентрових сил системи регулювання буде складати:

$$
M_{B}=\frac{1}{2} \omega^{2}\left[J_{T} \sin 2(\Omega-\varphi)-J_{J} \sin 2(\varphi+\Delta \varphi)\right] .(8)
$$

Підставимо у вираз (1) вирази для відповідних моментів (2), (5) та (8) i, враховуючи прийняті допущення, після перетворення отримаємо:

$$
\frac{k}{i}\left\{a+l\left[\sin \left(\Theta-\varphi_{0}\right)-\sin (\Theta-\varphi)\right]\right\} l \cos (\Theta-\varphi)=\frac{1}{2} \omega^{2}\left[J_{T} \sin 2(\Omega-\varphi)-J_{J} \sin 2(\varphi+\Delta \varphi)\right]
$$


Розв'язок рівняння (9) відносно $\omega$, та за умови, що $\omega=\frac{\pi n}{30}$, складе:

$$
n=\frac{30}{\pi} \sqrt{\frac{2 k\left\{a+l\left[\sin \left(\Theta-\varphi_{0}\right)-\sin (\Theta-\varphi)\right]\right\} l \cos (\Theta-\varphi)}{i\left[J_{T} \sin 2(\Omega-\varphi)-J_{J} \sin 2(\varphi+\Delta \varphi)\right]}},
$$

що є статичною характеристикою відцентрового регулятора при флюгерному регулюванні.

Для конкретного регулятора $J_{T}, J_{J}, i, k, l \in$ величинами, що не змінюються в процесі регулювання, і їх можна винести їх з-під знака радикала:

$$
n=\frac{30}{\pi} \sqrt{\frac{2 k l^{2}}{i J_{T}}} \sqrt{\frac{\left[\bar{A}+\sin \left(\Theta-\varphi_{0}\right)-\sin (\Theta-\varphi)\right] \cos (\Theta-\varphi)}{\sin 2(\Omega-\varphi)-\frac{J_{J}}{J_{T}} \sin 2(\varphi+\Delta \varphi)}},
$$

де $\bar{A}=\frac{a}{l}=\frac{F_{П p_{0}}}{k l}-$ величина початкового натягу пружини регулювання, що приведена до довжини кривошипа та жорсткості пружини.

При врахуванні одної з умов налаштування відцентрового регулятора на номінальну швидкість обертання ротора, а саме: $n=n_{\text {ном }}$ при $\varphi=\varphi_{0}$, маємо:

$$
n_{\text {ном }}=\frac{30}{\pi} \sqrt{\frac{2 k l^{2}}{i J_{T}}} \sqrt{\frac{\bar{A} \cos \left(\Theta-\varphi_{0}\right)}{\sin 2\left(\Omega-\varphi_{0}\right)-\frac{J_{J}}{J_{T}} \sin 2\left(\varphi_{0}+\Delta \varphi\right)}} .
$$

Вираз (12) дозволяє розрахувати номінальну швидкість обертання ротора при конструкційних параметрах відцентрового регулятора, а також вибрати параметри, що дозволяють виконати точне налаштування регулятора на $n_{\text {ном }}$ та оцінити вплив інших параметрів на номінальну швидкість обертання ротора при флюгерному регулюванні. Зазвичай [11] за параметри при налаштуванні регулятора на $n_{\text {ном }}$ вибирається величина початкового натягу пружини (параметр $\bar{A}$ ) або момент інерції відцентрових тягарців $J_{T}$, який може змінюватись за рахунок переміщення тягарців вздовж державок.

В разі, якщо величина початкового натягу пружини $\epsilon$ незмінною, тобто не $є$ параметром при налаштуванні регулятора на $n_{\text {ном }}$, то вираз для

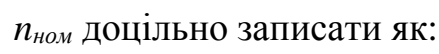

$n_{\text {ном }}=\frac{30}{\pi} \sqrt{\frac{2 l F_{I p_{0}}}{i J_{T}}} \sqrt{\frac{\cos \left(\Theta-\varphi_{0}\right)}{\sin 2\left(\Omega-\varphi_{0}\right)-\frac{J_{J}}{J_{T}} \sin 2\left(\varphi_{0}+\Delta \varphi\right)}}$.
Відповідно, вираз для величини початкового натягу пружини при налаштуванні регулятора на $n_{\text {ном }}$ за рахунок зміни моменту інерції відцентрових тягарців $J_{T}$ складе:

$F_{\Pi p_{0}}=\frac{i \omega^{2} J_{T}}{2 l} \frac{\sin 2\left(\Omega-\varphi_{0}\right)-\frac{J_{I}}{J_{T}} \sin 2\left(\varphi_{0}+\Delta \varphi\right)}{\cos \left(\Theta-\varphi_{0}\right)}$,

та, відповідно, вираз для моменту інерції відцентрових тягарців при налаштуванні регулятора на $n_{\text {ном }}$ за рахунок зміни величини початкового натягу пружини $F_{П p_{0}}$ :

$J_{T}=\frac{2 F_{\Pi p_{0}} l}{\omega^{2} i} \frac{\cos \left(\Theta-\varphi_{0}\right)}{\sin 2\left(\Omega-\varphi_{0}\right)}+J_{J} \frac{\sin 2\left(\varphi_{0}+\Delta \varphi\right)}{\sin 2\left(\Omega-\varphi_{0}\right)}$.

Для апроксимації результатів на інші типорозміри даного регулятора вираз (11) у відносних величинах, а саме $\bar{n}=\frac{n}{n_{\text {ном }}}$, становитиме: 


$$
\bar{n}=K_{M} \sqrt{\frac{\left[\bar{A}+\sin \left(\Theta-\varphi_{0}\right)-\sin (\Theta-\varphi)\right] \cos (\Theta-\varphi)}{\sin 2(\Omega-\varphi)-\frac{J_{I}}{J_{T}} \sin 2(\varphi+\Delta \varphi)}},
$$

де $K_{M}$, відповідно, запишемо як:

$$
K_{M}=1 / \sqrt{\frac{\bar{A} \cos \left(\Theta-\varphi_{0}\right)}{\sin 2\left(\Omega-\varphi_{0}\right)-\frac{J_{J}}{J_{T}} \sin 2\left(\varphi_{0}+\Delta \varphi\right)}}
$$

Вирази (16) та (17) дозволяють побудувати статичні характеристики відцентрового регулятора у відносних координатах при таких параметрах регулятора:

- кута між хордою лопаті й вектором моменту інерції лопаті - $\Delta \varphi$;

- кута між хордою лопаті й державками відцентрових тягарців $-\Omega$;

- кута між кривошипом і хордою лопаті - $\Theta$;

- жорсткості пружини регулювання, що визначається параметром $-\bar{A}$;

- при різних співвідношеннях моментів інерції лопаті та відцентрових тягарців $-\frac{J_{J}}{J_{T}}$.

Висновки. 1. Проведений аналіз технологічних можливостей та тенденцій виготовлення лопаті на сьогоднішній день показав, що вони передбачають отримання максимального коефіцієнта використання енергії вітру ротором i, відповідно, максимальне наближення реального профілю лопаті до розрахункового. В сучасних лопатях використовують розширення лопаті від кінця до комеля в межах від 1:2 до 1:4 і закрут лопаті сягає $30^{\circ}$, тобто відхилення напрямку вектора моменту інерції лопаті від хорди лопаті може складати до $20^{\circ}$.

2. Запропоновано удосконалену математичну модель відцентрового регулятора ротора вітроустановки при флюгерному регулюванні з урахуванням кута між хордою лопаті й вектором моменту інерції лопаті, що дало можливість отримати вирази для визначення статичних характеристик відцентрового регулятора залежно від його параметрів, а також уточнити вирази для визначення параметрів відцентрового регулятора, які використовуються при його налаштуванні для отримання необхідних номінальних обертів ротора вітроустановки.

1. Жуковский H.E. Теория регулирования хода машин. Т.4. М. Л. ОНТИ НКТП СССР. 1938. 324 с.

2. Максвелл Д.К., Вышнеградский И.А., Стодола А. Теория автоматического регулирования. Лианезированные задачи. М. АН СССР. 1949. $431 \mathrm{c.}$

3. Цукерник Л.М. Теория и расчет центробежного регулятора. М. Машгиз. 1951. $110 \mathrm{c}$.

4. Сабинин Г.Х. Теория регулирования быстроходных ветродвигателей поворотом лопастей центробежным регулятором. Промышленная аэродинамика. 1957. Сб. № 8. С. 5-77.

5. Сабинин Г.X. Теория регулирования быстроходных ветряков центробежным регулятором с помощью поворота лопастей. Вопросы энергетики. 1959. C. 37-49.

6. Шефтер Я.И. Рождественский И.В. Ветронасосные и ветроэлектрические агрегаты. М. Колос. 1967. $376 \mathrm{c}$.

7. Шефтер Я.И. Использование энергии ветра. М. Энергоатомиздат. 1983. $200 \mathrm{c.}$

8. Перли С.Б. Быстроходные ветряные двигатели. М. Л. ГЭИ. $1951.216 \mathrm{c.}$

9. Коваленко В.И., Коханевич В.П., Шихайлов Н.А. Ветроэлектрическая установка мощностью 2 кВт. Энергетика и электрификация. 1991. № 4. С. 37-40.

10. Коваленко В.И., Коханевич В.П., Шихайлов Н.А. Ветроэнергетические установки малой мощности. Энергетика и электрификация. 1993. № 1. С. 43-46.

11. Коханєвич В.П. Статичні характеристики відцентрового регулятора при флюгерному регулюванні ротора вітродвигуна. Відновлювана енергетика. 2008. № 1 (12). C. $39-44$.

\section{REFERENCES}

1. Zhukovsky N.E. Teoriya rehulyuvannya khodu mashyn. [Theory of regulation of the course of machines]. Vol. 4. Moskow Leningrad. ONTI NKTP USSR. 1938. 324 p. [in Russian].

2. Maxwell D.K., Vyshnegradsky I.A., Stodola A. Teoriya avtomatychnoho rehulyuvannya. Lianezirovannye zavdannya. [Theory of automatic control. Lianised problems. Moskow. USSR Academy of Sciences. 1949. 431 p. [in Russian].

3. Tsukernyk L.M. Teoriya i rozrakhunok vidtsentrovoho rehulyatora. [Theory and calculation of a centrifugal regulator]. Moskow. Mashgiz. 1951. 110 p. [in Russian].

4. Sabinin G.H. Teoriya rehulyuvannya shvydkokhidnykh vitrodvyhuniv povorotom lopatey 
vidtsentrovym rehulyatorom. [Theory of regulation of highspeed wind turbines by turning blades by a centrifugal regulator. Industrial aerodynamics]. 1957. Sb. No. 8. Pp. 5-77. [in Russian].

5. Sabinin G.H. Teoriya rehulyuvannya shvydkokhidnykh vitryakiv vidtsentrovym rehulyatorom za dopomohoyu povorotu lopatey. [The theory of regulation of high-speed windmills by a centrifugal regulator by means of rotation of blades]. Energy issues. 1959. Pp. 37-49. [in Russian].

6. Shefter Ya.I., Rozhdestvensky I.V. Vetronasosnaya i vitroelektrychni ahrehaty. [Wind pump and wind power units]. Moskow. Colossus. 1967. 376 p. [in Russian].

7. Shefter Ya.I. Vykorystannya enerhiyi vitru. [Use of wind energy]. Moskow. Energoatomizdat. 1983. 200 p. [in Russian].

8. Perli S.B. Shvydkokhidni vitryani dvyhuny. [Highspeed wind turbines]. Moskow - Leningrad. GEI. 1951. 216 p. [in Russian].
9. Kovalenko V.I., Kokhanevich V.P., Shikhailov N.A. Vitroelektrychnoyi ustanovky potuzhnistyu $2 \mathrm{kVt}$. [Wind power plant with a capacity of $2 \mathrm{~kW}$ ]. Energy and electrification. 1991. No. 4. S. 37-40. [in Russian].

10. Kovalenko V.I., Kokhanevich V.P., Shikhailov N.A. Vitroenerhetychni ustanovky maloyi potuzhnosti. [Low power wind turbines]. Energy and electrification. 1993. No. 1. Pp. 4346. [in Russian].

11. Kokhanevich V.P. Staticheskiye kharakteristiki tsentrobezhnogo regulyatora pri flyugernoy regulirovanii rotora nepodvizhny. [Static characteristics of the centrifugal regulator at weather vane regulation of the rotor of the wind turbine]. Vidnovluvana energetika. 2008. No. 1(12). Pp. 39-44. [in Ukrainian].

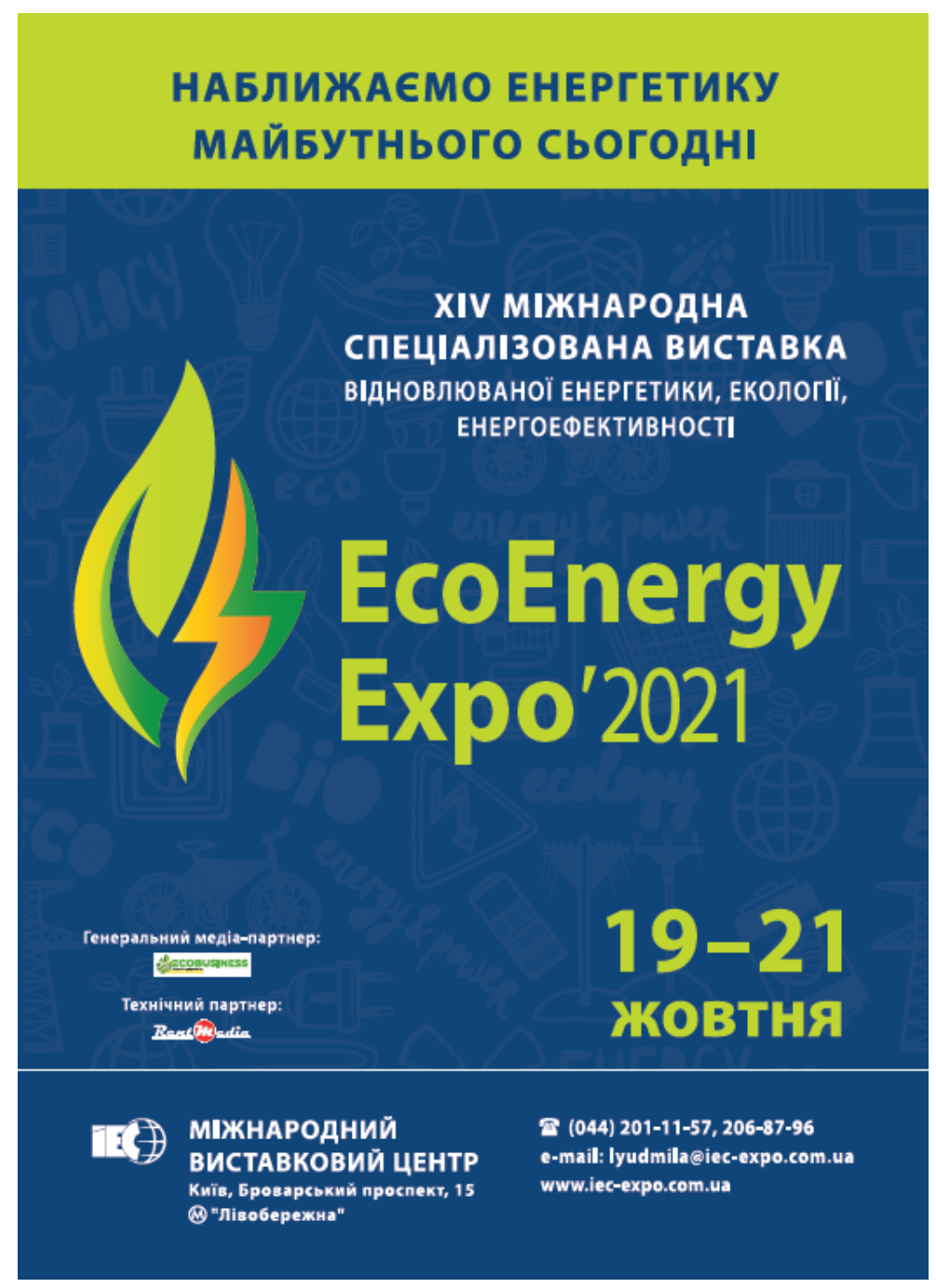

